\title{
sobre: Buenos Aires transmedial: Los barrios de Cucurto, Casas e Incardona, de Carolina Rolle.
}

\author{
Rosario: Beatriz Viterbo, 2017. \\ ARY PIMENTEL Universidade Federal do Rio de Janeiro, Brasil / ary.pimentel@yahoo.com.br
}

\section{A cidade narrada por estratégias transmidiais na literatura do presente: a invasão transmidiática do espaço narrativo}

A pesquisadora Regina Dalcastagnè afirma que a literatura contemporânea reflete nas suas ausências talvez muito mais do que naquilo que diz explicitamente através da fatura do texto. Isso é algo que vale para a literatura brasileira e para a literatura dos diferentes países do continente. Após um exaustivo estudo quantitativo da produção narrativa que envolveu todos os romances publicados pelas principais editoras brasileiras ao longo de um período de quinze anos (entre 1990 e 2004), ela concluiu que 72,7\% dos autores eram homens, e 93,9\% eram brancos. Soma-se à homogeneidade racial e de gênero a predominância geográfica (60 \% deles vivem no Rio de Janeiro e em São Paulo) e profissional (quase todos tiveram sua formação relacionada a espaços privilegiados de produção de discursos: os meios jornalístico e acadêmico). Poderíamos acrescentar a variante territorial a essa discussão. $O$ grupo dominante no campo da produção de narrativas mora em alguns poucos bairros das zonas mais ricas dessas duas cidades.

Só mais recentemente, em países como Argentina e Brasil, a cidade passa a ser narrada com mais frequência sob a perspectiva de um novo olhar e a partir de um novo lugar da cidade ou, melhor dizendo, a partir de um novo lugar da cultura, como propõe Homi Bhabha. A bagagem cultural desses novos autores que começam a publicar nas últimas duas décadas não se associa obrigatoriamente à literatura canônica, muito pelo contrário, está marcada por vários outros tipos de mediações com o mundo, em geral as associadas à palavra cantada, à imagem que circula em publicações populares ou à imagem em movimento que chega aos distantes lares das periferias.

No Brasil, publica-se em 2015 o livro O meu lugar, cujo título faz referência a um conhecido samba sobre o subúrbio de Madureira. A obra traz textos de autores que reivindicam, em histórias e memórias, a singularidade de seus bairros. Essa visão do microterritório urbano construída a partir de uma relação de profunda intimidade com áreas da cidade que foram tradicionalmente subrepresentadas é uma novidade.

Para citar este artículo: Pimentel, A. (2019). Sobre: Buenos Aires transmedial: Los barrios de Cucurto, Casas e Incardona, de Carolina Rolle. El taco en la brea, 10 (junio-noviembre), 240-243. Santa Fe, Argentina: UNL. DOI: $10.14409 /$ tb.v1i10.8706 
A partir do final do século XX, diante de profundas transformações sociais, políticas, econômicas e culturais, outros autores (ou autores Outros) surgem na cena literária dos dois países e passam a afirmar seus conhecimentos e seus territórios, bem como os discursos midiáticos que haviam ajudado a formar o seu olhar. Começava-se a questionar o que o cânone dos sistemas de representação tinha deixado de fora do retrato. Os novos sujeitos, que são esses autores improváveis despontando na cena literária do século XXI, implicam a emergência de novos objetos, novos problemas, novos personagens e novos territórios da cidade.

Diante disso, poderíamos concluir que, construído a partir dos lugares hegemônicos da cidade letrada, o sistema de representação literária não conta a história de certos bairros da cidade e de seus sujeitos populares. A emergência de novos autores, oriundos de lugares alheios ao contexto dominante, traz consigo temas e abordagens características de certos microterritórios invisibilizados e rompe com a sub-representação de sujeitos subalternizados e territórios periféricos, estabelecendo-se uma nova relação com o urbano. Negros, pobres, favelados e nordestinos (no caso do Rio de Janeiro), villeros, migrantes de países limítrofes e moradores do conurbano (no caso de Buenos Aires), que foram excluídos do protagonismo no imaginário a respeito das duas cidades, agora invadem a cena literária.

Destaque especial, nesse contexto, merecem as linguagens populares e massivas que se impõem no lugar da palavra escrita como as mediações dominantes entre homem e mundo. Já que, conforme observa Vilém Flusser, o mundo não nos é acessível imediatamente, as imagens e os discursos imagéticos das distintas mídias massivas têm o papel de nos apresentar o mundo, convertendo-se numa espécie de mapas da realidade que nos cerca e com a qual não estabelecemos contato direto. Constituem-se, assim, novas poéticas baseadas nos imaginários suburbanos ou periféricos e num universo atravessado por diferentes «meios» ou mídias.

Na edição de Villa Celina: El ataque a Villa Celina, publicada pela editora Eloísa Cartonera, em 2007, Juan Diego Incardona reconhece que, ao chegar ao curso de Letras da Universidad de Buenos Aires, tinha apenas uma série de leituras desordenadas. Havia lido autores populares como Julio Verne e H. G. Wells, e outros como Mark Twain e Salinger. Entre os argentinos, apenas Ernesto Sábato. É na faculdade que ele passa a ter «una idea de la literatura» (6). Aí conheceria Jorge Luis Borges, Esteban Echeverría e tantos outros. Contudo, seus textos, nos quais o lócus de enunciação recorrente é ao bairro onde nasceu, ecoam as letras do «rock chabón» das periferias e o conteúdo dos programas de televisão de grande apelo popular assistidos pela sua geração.

Por sua vez, Washington Cucurto, outro autor nascido em um município da Grande Buenos Aires, revela a presença dos pobres que circulam pela cidade e focaliza os territórios invisibilizados do urbano a partir das novas poéticas transmidiais, destacando-se, no seu caso, as marcas deixadas no texto literário pela leitura de histórias em quadrinhos, algo bastante presente no processo formativo do autor.

Por meio da palavra escrita e da mediação de várias outras linguagens fundadas na imagem, novos autores oriundos das periferias, que agora estão em toda parte, redescobriram o bairro como território da literatura. A opção crescente pela temática dos bairros revela poéticas narrativas que investem no microterrítório ou naquilo que Josefina Ludmer chamou de islas urbanas, espaços que ganham sentido como constructos sociais criados através das relações humanas. Trata-se de pequenos territórios, partes e parcelas da cidade, a partir das quais se estruturam os sentidos de uma unidade temática no tecido labiríntico e inabarcável do urbano, ou, como diz Carolina Rolle, «el barrio se constituye en un elemento temático, una estructura de sentido, dentro de las obras» (15). 
Tudo isso para chegar ao livro lançado por uma pesquisadora da Universidad Nacional de Rosario que ecoou por esses pagos brasileiros onde Carolina Rolle esteve desenvolvendo um trabalho comparatista que envolvia uma mirada contrastiva entre a nova literatura dos bairros de Buenos Aires e do Rio de Janeiro.

A narrativa do presente nessas duas cidades muitas vezes se apresenta como uma espécie de cartografia do urbano a partir de miradas microlocalizadas. O significativo título de uma antologia que traria contos de vários narradores daquela que, à falta de um nome melhor, se convencionou chamar de Nueva Narrativa Argentina, (Buenos Aires/ escala 1:1. Los barrios por sus escritores), exemplifica essa maneira como «el barrio se inscribe en la historia del sujeto como la marca de una pertenencia indisoluble» (Rolle:47).

Nessas poéticas centradas nos microterritórios urbanos, os autores imaginam seus bairros a partir da experiência e de seu lugar de consumo cultural. Trata-se de poéticas atravessadas pelo vivido, numa espécie de escrevivência que traz à tona as dimensões mais íntimas da subjetividade juntamente com as experiências de recepção da cultura. Esses produtos da cultura de massa que chegam predominantemente às regiões oriundas dos processos de periferização, suburbanização ou conturbação circulam através de uma pluralidade de formas imagético-discursivas a partir das quais se constitui a «imaginação pública» (Ludmer, 2010). A recepção também acaba por ser uma das formas da experiência urbana e suburbana. As novas «poéticas barriales», que emergem das obras de autores como Incardona, Cucurto ou Fabián Casas, mobilizam uma verdadeira arte combinatória na qual se atualiza um quebra-cabeças de referências e materiais relativamente espúrios oriundos da música popular, dos quadrinhos e da televisão, em maior medida. Esse pensamento traduz o novo tratamento do microterritório urbano e é o ponto de partida para o projeto de leitura crítica levado a cabo por Carolina Rolle, o qual daria origem ao livro Buenos Aires transmedial: los barrios de Cucurto, Casas e Incardona.

Um elemento chave para a leitura realizada por Carolina Rolle é o conceito de intermedialidade que a autora vai buscar a partir da obra do artista britânico Dick Higgins e que pode ser entendido como a mistura de meios/mídias/linguagens que se impõe na dicção de um artista, privilegiando o entre-lugar das mídias na perspectiva da produção e da leitura de suas obras. Cucurto, por exemplo, trabalha com materiais saqueados do campo canônico e com restos ou refugos da linguagem de meios massivos. Mescla a linguagem de outras artes e de outros meios típicos da comunicação de massa com elementos oriundos do plágio ou da antropofagia, que ele insiste em denominar estética del choreo (estética do roubo).

Há aqui uma clara mudança de paradigmas. Essa produção narrativa de sujeitos que destoam do perfil dos predominadores - como chamava Carolina Maria de Jesus aos integrantes do campo hegemônico que têm as mesmas profissões, vivem nas mesmas cidades, têm a mesma cor e o mesmo sexo- visibiliza territórios e sujeitos negados, investindo na representação como uma forma consciente de transgressão social e de desestabilização das regras da arte e do próprio conceito de literatura. Demonstra-se com isso que outra configuração do campo literário é possível.

Deste modo, esse livro coloca um desafio frontal para a formação de uma crítica literária atual sobre as narrativas do urbano, que é pensar essa produção recente a partir da lógica própria de autores que propõem uma nova poética a partir de imaginarios urbanos barriales e, no limite, disputam os sentidos de um novo conceito de literatura, formulado agora a partir de uma outra experiência de cidade e de uma outra experiência da cultura, já não mais centrada na palavra escrita e sim muito mais envolvida com uma dimensão transmidial da linguagem. 
Bela chave de leitura para uma aproximação à literatura do presente, que foi trazida à luz pelas estéticas e dicções de autores saídos da realidade dos bairros e periferias de Buenos Aires e do Rio de Janeiro. Não é todo dia que o resenhador tem diante de si um livro como o de Carolina Rolle: obra praticamente inesgotável para o leitor que se propõe a pensar as narrativas do presente, texto agudo e inovador de leitura irresistivelmente saborosa, iluminando um período recente, mas já fundamental no processo de produção de representações da cidade.

\section{Referências bibliográficas}

Martín-Barbero, J. (2001). Dos meios às mediações: comunicação, cultura e hegemonia, 2da ed. Rio de Janeiro: UFRJ. Tradução de Ronald Polito e Sérgio Alcides.

Bhabha, H.K. (1998). O local da cultura. Belo Horizonte: UFMG. Tradução de Myriam Ávila, Eliana Lourenço de Lima Reis e Gláucia Renate Gonçalves.

Dalcastagnè, R. (2012). Literatura brasileira contemporânea: um território contestado. Vinhedo, Rio de Janeiro: Horizonte, Editora da UERJ.

Duarte, C.L.; Côrtes, C. e Pereira, M. do R.A. (Orgs.) (2016). Escrevivências: identidade, gênero e violência na obra de Conceição Evaristo. Belo Horizonte: Idea.

Flusser, V. (2011). Filosofia da caixa preta: ensaios para uma futura filosofia da fotografia. São Paulo: Annablume.

Incardona, J.D. (2007). El ataque a Villa Celina. Buenos Aires: Eloisa Cartonera.

Jesus, C.M. de (2014). Diário de Bitita. São Paulo: SESI-SP.

Ludmer, J. (2010). Aquí América Latina: una especulación. Buenos Aires: Eterna Cadencia.

Simas, L.A. e Moutinho, M. (Orgs.) (2015). O meu lugar. Rio de Janeiro: Mórola.

Terranova, J. (Org.) (2011). Buenos Aires/ escala 1:1. Los barrios por sus escritores. Buenos Aires: Entropía. 